\section{Clothing of righteousness: exploring tensions of halal maternity wear on online apparel websites}

\author{
Jayne Krisjanous, Nilufar Allayarova and Djavlonbek Kadirov \\ School of Marketing and International Business, Victoria University of Wellington, \\ Wellington, New Zealand
}

Tensions of halal maternity wear

Received 20 March 2020 Revised 22 May 2020 14 July 2020 29 September 2020 Accepted 25 November 2020

\begin{abstract}
Purpose - This paper aims to explore marketing practices related to online halal maternity wear by examining the characteristics of halal maternity wear promoted to Muslim women (Muslimah) and how these differ between sponsoring websites.
\end{abstract}

Design/methodology/approach - A qualitative content analysis of 24 websites promoting halal maternity wear to pregnant customers was undertaken.

Findings - Several issues related to the availability and promotion of halal maternity wear online, particularly when addressing the needs of Western Muslim women, were found. Successful marketing solutions to the problems of halal maternity wear require solving a number of tensions arising at the intersections of the following distinctions: mahram versus non-mahram settings, crude versus stylish fashion and the normative perceptions of immodesty versus modesty.

Practical implications - Careful research and attention need to be taken before promoting and targeting products as appropriate for Muslimah maternity wear. Those brands that display the requisite skills and knowledge necessary to determine whether a product meets the needs of modesty, fashionability and local climate/weather conditions in their maternity lines have much to gain from the Muslimah maternity market.

Social implications - The availability of maternity wear that makes Muslimah feel comfortable and satisfied with their appearance will contribute to a positive pregnancy body image. Positive pregnancy body image is associated with positive pre and postnatal infant attachment by the mother, which in turn leads to beneficial outcomes for mother and baby.

Originality/value - Research to date has focused on Islamic fashion in general, with a dearth of research on Islamic maternity wear. This paper addresses the gap by focusing on maternity wear and associated marketing practices, from the Islamic point of view.

Keywords Content analysis, Islam, Islamic fashion, Halal maternity wear, Muslimah, Online maternity wear

Paper type Research paper

\title{
Introduction
}

Pregnancy is an important time in a woman's life, where significant physical and psychological changes occur to accommodate a growing baby and prepare for impending birth. A key task in this journey, particularly from the second trimester, is to acknowledge pregnancy-induced physical changes and respond positively to them (Miller, 2014). This includes switching from one's regular non-pregnant apparel to clothing that can accommodate increasing abdominal girth as well as changes to other parts of the body. Transitioning into maternity wear can be described as a pregnancy "rite of passage", where display of the pregnant body in garments

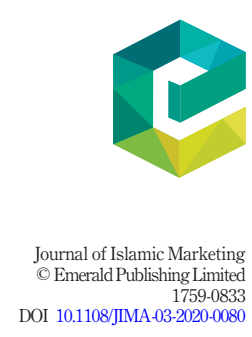


that contain, without constraining the pregnant body, demonstrates an outward acceptance of pregnancy changes, as one "gives in" to a deviation from a "normal" shape. As well as the physical aspect, the adoption of maternity wear is also tied to complex psychological meanings, embedded in one's self-concept and image (Ogle et al., 2013; Sohn and Bye, 2015). The adoption of scripted behaviours that are consistent with norms imposed by culture, religion and/or tradition will also impact significantly on clothing selected as appropriate. In turn, these decisions will influence and guide consumption practices and purchase decisions (Longhurst, 2005).

Appropriateness perceptions of maternity wear are context-specific. Although there has been some loosening of boundaries around what constitutes appropriate pregnancy apparel, particularly in "Western" societies (Europe, Australasia and the Americas), some contextual style differences (prevalently socio-cultural) in what is considered to be appropriate may still be discerned. In light of retailers producing varied clothing lines promoted as specifically maternity wear, most non-Muslim pregnant women perceive themselves to be relatively free to adopt a style they desire. For these Western women, a social context would dictate whether to wear elasticated tighter "active wear" for as long as it is comfortable, or conversely, loose tops and trousers drawn from non-pregnant casual clothing ranges. In some cultural settings, exposure of the naked pregnant abdomen in public may be seen as appropriate. However, work dress requires adherence to the pervading rules or norms of the job. Even then, pervasive liberalisation has led to few expectations that the general style of clothing will need to change radically, except for what is needed to accommodate a wider girth comfortably. Within Western markets, maternity wear, once modest and considered a specialist product, is now offered by many high street brands as part of their overall product offering. For pregnant consumers, the rise in internet apparel websites, where clothing can be purchased online with relative ease provides opportunity to source, select and obtain appropriate garments for their pregnancy. The problem is that these retailers predominantly cater for the needs arising from contextual sensitivities pertaining to secular/liberal maternity wear, while ignoring other non-secular sensitivities. Apparently, perceived "freedom" may not represent true emancipation as such, but a commercial hegemony of promoting a particular lifestyle.

For women who adhere to cultural or religious expectations and their associated rules or rituals of pregnancy, the norms of maternity wear may be radically different (Cassar, 2006; Hassan et al., 2019). With the standards and expectations set for these women, having access to markets where the correct clothing is available for purchase is important. At the same time, for brands promoting culturally appropriate maternity wear, an online presence provides significant opportunity to reach markets by increasing visibility and access for prospective customers to their products. Yet, despite maternity apparel being a potentially lucrative market for manufacturers, there is little research existing that examines how such clothing is assembled for display, promoted and sold via the internet. In particular, there is a dearth of research that investigates the phenomenon of halal maternity wear for sale online. A study by Behrman and Erman (2019) conducted on women living in a Western country (France) found:

Muslim women have, on average, higher ideal family sizes than non-Muslim women, which can largely be explained by higher religiosity and higher numbers of siblings (the latter proxies for norms favoring large families (p. 617).

This would mean that pregnant Muslimah require to dress in maternity wear more often than non-Muslim across the years of fertility, resulting in a higher demand for maternity clothing per individual customer. Moreover, reinforcing the perception of "the clash of 
civilizations", a myopic perspective would tend to see "halal" or "Islamic" fashion as the direct opposite of what is considered to be "Western" fashion (Wilson and Grant, 2013). Accepting Wilson and Grant's (2013) notion of cultural osmosis, we argue that secular maternity wear and halal maternity wear differ with regard to their distinct contextual differentiation. If mainstream maternity wear undergoes modifications under the effect of secular distinctions (i.e. casual/work, privacy/public), halal maternity wear similarly adapts to different contextual distinctions based on religious sensitivities (privacy/family, mahram/ non-mahram). We define halal maternity wear as apparel tailored for a pregnant Muslim woman which is not only designed to allow for the changes in body size during pregnancy, but also that is tailored taking religiously-derived specific situations and distinctions into account. It must be noted that halal maternity wear falls under the category of "worn halal" (Wilson, 2014).

Using qualitative content analysis, this article explores maternity wear suggested as halal promoted for purchase on internet websites. The context of our study is broadly positioned as Muslim women (Muslimah) living in countries with a strong Western orientation who are therefore exposed to Western forces as a part of their daily life. The study aim is to provide insights into the nature of halal maternity wear, the extent to which the clothing available achieves halal standards, and in what ways. The two research questions are:

$R Q 1$. What are the nature and characteristics of halal maternity wear promoted to Muslim women living in the West and to what extent is there variability between sponsoring websites?

RQ2. What issues and tensions can be observed to arise from the marketing of maternity wear promoted as "halal" or appropriate for these women?

To address these research questions, this article takes the following course: First, the relevant conceptual background to our study is given. Next, the study method is outlined. Content analysis findings are then described and identified categories/themes nominated. This is then followed by discussion and conclusions.

\section{Conceptual background}

Pregnancy and Muslim women

The distinct conception of pregnancy within the Muslim faith influences understandings, practices, attitudes and behaviours of Muslim women (Hassan, 2017; Hassan et al., 2019). Within broader socio-cultural communities, Muslim women seek knowledge of Islamically appropriate pregnancy conduct in teachings, customs and rituals, in addition to professional health support (Hammoud et al., 2005; Hassan, 2017; Merits et al., 2018; Williams, 2018). The teachings of Qur'an and Hadith (the prophet's life and sayings recorded by followers) are the main sources of behavioral guidelines for Muslims. Islam rewards motherhood, with pregnancy considered a blessed time in a woman's life (Ghodrati and Akbarzadeh, 2018). The following words of the Prophet Muhammad (SAW) merits the mother's effort for giving birth to a child through the phrase "Paradise is under the feet of your mother" (Source: Sunan al-Nasā'i 3104; graded as sahih (authentic) according to Al-Albani), meaning that attaining Heaven is directly linked to respect, care, and service shown to one's mother. During pregnancy, devoted Muslim women seek assurance in Qur'anic injunctions and Prophetic sayings, often referring to them to address their worries, to maintain personal calm and focus, and avoid distractions. The chapters of Qur'an relevant to pregnancy and childbirth are Ali' Imran (the Family of Imran) and Maryam (Mary). These chapters include 
prayers for pregnant women while encouraging them to strengthen hope during hardship and distress. Some of the Islamic guidelines for appropriate behaviour during pregnancy include modesty, being discreet about pregnancy in public (among other than immediate family), being grateful to Allah for being pregnant, consuming food considered pure (halal), avoiding certain foods that are considered harmful or non-halal and offering frequent prayers for both themselves and the child. Muslim women, as any other Muslim, must eat halal, avoid sinful or unrighteous acts (e.g. smoking or drinking alcohol) and wear modest clothing (Kadirov et al., 2016). For the families expecting a child, these responsibilities become ever more important, as it is believed that the behaviour of the parents during pregnancy can highly impact the child's health, well-being and his/her subsequent behaviour. Therefore, prospective parents are recommended to be vigilant toward their own diet and behaviour to protect their child from harm (https://islamhashtag.com/healthy-foodin-pregnancy-sunnah/). The following ayah in Qur'an sets the expectations of modest clothing:

"O children of Adam, we have bestowed upon you clothing to conceal your nakedness (private parts) and as adornment (fine clothes). But the clothing of righteousness - that is "khayr" (the best, the finest, the most charitable, well-being enhancing). That is from the signs of Allah that people may take heed" (Qur'an, 7:26).

In this ayah (verse), the three main purposes of wearing different clothing are described:

- clothing worn to conceal nakedness;

- clothing worn to adorn oneself; and

- clothing worn to develop, exhibit and maintain righteousness.

This ayah sets the principle of Islamic wear: it should be something that supports and promotes righteousness (Kadirov, 2014). In several ayahs, a general way of dressing in public is prescribed:

And say to the believing women that they should lower their gaze and guard their modesty; that they should not display their zeenah (charms, or beauty and ornaments) except what (must ordinarily) appear thereof; that they should draw their khimar (veils) over their bosoms and not display their zeenah except to their husbands, their fathers [...]. and that they should not strike their feet so as to draw attention to their hidden zeenah (ornaments). (Qur'an 24:31-32)

O Prophet! Tell your wives and daughters and the believing women that they should draw over themselves their jilbab (outer garments) (when in public); this will be more conducive to their being recognized (as decent women) and not harassed. But God is indeed oft-forgiving, most merciful (Qur'an 33:59).

And know that women advanced in years, who no longer feel any sexual desire incur no sin if they discard their thiyab (outer garments), provided they do not aim at a showy display of their zeenah (charms or beauty). But it is better for them to abstain (from this); and God is all-hearing, all-knowing (Qur'an 24:60).

It is evident from these ayahs that Qur'an emphasises modesty, while the rulings in themselves are broad and contextual depending on one's location (i.e. public), risk of harassment and age. Moreover, Muslim women are advised to avoid wearing tight, transparent and abnormal/conspicuous clothes in public (Qaradawi, 1995). In one of the prophetic hadiths, Aisha said, "Asma, daughter of Abu Bakr (that is, Aisha's sister), entered upon the Apostle of God (SAW) wearing thin clothes. The Apostle of God turned his attention from her and said, "O Asma, when a woman reaches the age of menstruation, it 
does not suit her except that she displays parts of her body except this and this," and he pointed to her face and hands (Sunan Abi Dawud). Hence, Muslim women are expected to wear clothing consistent with the early practice of Muslims and the generally accepted scholarly teachings of Islam. There are two different settings: mahram (private) and nonmahram (public). The Islamic distinction of the "mahram" setting versus the "non-mahram" setting is distinct to the Western idea of the private setting versus the public space (Boulanouar, 2006). The "mahram" is a socio-cultural space within which a woman can have a relative degree of freedom regarding her clothing choice. Less restrictions apply on the type and style of clothes they can wear in privacy (not in public). However, this freedom is not absolute: it might vary from personal privacy to that of family gatherings where modest clothing would be preferable. In contrast, by Islamic law, veiled Muslim women must consider wearing modest clothing when they are in public. Modesty is a general principle, which is based on a number of broad, culturally fluid recommendations. Also, the concept of "awrah" needs to be taken into consideration. Awrah refers to "parts of human body which in principle should not be seen by other people except in an emergency or urgent need" (Karyono et al., 2017, p. 3450). The definition of women "awrah" varies in mahram versus non-mahram settings. The body areas considered intimate as by the teachings of Islam fluidly changes as the woman's secluded company expands starting from her spouse, children, immediate family, distant family, Muslim women, non-Muslim women, those who are ineligible for potential marriage, and all others.

\section{The pregnant body and maternity wear}

Pregnancy is a liminal life stage within the childbearing years (Ogle et al., 2013), where health and wellness can most often be expected and enjoyed. However, the image of the pregnant body is often regarded as one that transgresses normal spatial and cultural boundaries (Russo, 1995). One way to re-contextualise the potentially transgressive pregnant body and legitimise it is through maternity wear that contains the body (Musial, 2003). However, despite pregnancy being an alteration from the highly mediated and sexualised image of what is considered the ideal female shape, pregnancy clothing still requires certain attributes considered attractive to the wearer. Also, perinatal mental health is extremely important for pregnant Muslimah who attempt to maintain a balance between body and mind in addition to controlling Earthly self (i.e. bodily desires) in reference to Heavenly spirit (i.e. religious righteousness) (Zaidi, 2017). Specifically, good health might help Muslimah to feel better about themselves, as there is an assumption that mental problems are linked to weak faith (Zaidi, 2017).

While changes to clothing may be required as early as 12 weeks into the pregnancy, in general, the transition to maternity wear occurs around 16-20 weeks gestation (Anand, 2012). Maternity wear provides physical benefits (practical support and comfort) with its primary function and design to accommodate expanding abdominal girth, increase in overall body fat deposits and breast changes. The adoption of pregnancy wear also signals to the outside world the wearer's current pregnant state (Anand, 2012; Longhurst, 2005; Ogle et al., 2013). Furthermore, with pregnancy a liminal state, Ogle et al. (2013) suggest maternity dress is instrumental in shaping the self and identity through this period. Feeling positive about one's appearance in pregnancy has a positive association with health and psychosocial well-being, which in turn increases the likelihood of high levels of pre and postnatal attachment to the baby, which are strongly correlated with positive outcomes for mother and baby (Earle, 2003; Johnson et al., 2004; Krisjanous et al., 2014; Strang and Sullivan, 1985). Longhurst (2005), studying maternity wear in a Western context, concluded that especially for first time pregnant women making the transition to motherhood, clothing 
the body can be a complex act. Much can be read about their subjectivities by "what they reveal, what they conceal, what images they create, for whom and where" (p. 433).

Kim et al. (2010) suggest that maternity wear on sale needs to integrate functionality, aesthetics and marketability. Despite, maternity wear's functionality, features such as elegance, fashionability and concealment (or showcasing) of changing shape are also sought by wearers (Ogle et al., 2013). However, maternity clothing can be expensive when potential usage is considered against opportunity to wear (approximately five months). Moreover, women often look forward to ceasing the wearing of maternity clothing as soon as possible after the birth of the baby as a sign of returning to their pre-pregnant "conforming" state (Anand, 2012). Many brands counter the relative expensive cost of items versus low usage potential by increasing perceived functionality and added benefits for the buyer. For example, the offering of lines that are versatile for breast feeding and/or suitable for post-partum wear can potentially offer purchase incentives to customers.

Recommendations concerning maternity attire for Muslim women include the following: the whole body is to be covered properly except the face; the garment should be loose enough to not highlight or disclose the shape of the body; the fabric of the clothes should not be see-through; all clothing should be "decent" by cultural norms; women should wear feminine clothes, while avoiding masculine styles. In practice, however, not all women strictly follow these.

\section{Islamic fashion and the principle of modesty}

Today, in the West, most diasporic and Western-born Muslim women wear apparel that adheres to the rules of Islamic modesty. Such "modest" wear is often juxtaposed against the appearance of Western women, whose streetwear fashion is less restrictive. However, Mossière (2012) claims that for Muslim women to adhere to the ruling of modesty, this does not necessarily mean wearing clothes with oriental designs, or those that are purely loose and baggy. Zahra Aljabri, co-founder of the online marketplace Mode-esty (Lesley, 2016) talking of the difficulties in sourcing modest yet fashionable wear suggests:

[...] stylish, modest clothes are very hard to find in the mainstream marketplace. Modest dressers routinely piece their outfits together from sleeveless, sheer, mini and backless options like a game of Tetris. We're often forced to add haphazard layers to get the coverage we need. This is even though the demand for modest fashion is massive (see www.worldreligionnews.com/?p=30474).

Aliabri continues that brands should have knowledge of Muslim women's understanding of modesty and that small details such as a slit in a skirt or a see-through top would determine whether Muslim women would purchase the clothing item.

Indeed, fashion practices among Muslim women are strongly impacted by global trends, including migration, exposure to non-Islamic cultures, and the rise of media with substantial reach and personal connectivity (Haddad and Smith, 2014). Increasingly today, many young Muslimah are interpreting Islam in a context where Muslims are a minority religious group, thus combining Islamic female wear principles with commonplace ideological understandings of female status. For many younger Muslimah, an increasing focus on fashion that is modest yet stylish and fashionable is leading to a trend characterised by a fusion of "fashion with piety" (Jones, 2007). By participating in the fashion industry as designers and boutique owners, some Muslim women are starting to produce distinct Muslim-Western fashions, visible both in-store and online (Akou, 2007). With the childbearing years and potential for pregnancy part of the life stage of this producer group and their customers, it stands to reason that maternity fashions will also be affected by these trends and a desire to both uphold modesty principles and look and feel good while wearing maternity clothing. 


\section{Method}

To address the research questions, a qualitative content analysis method was used. Due to the exploratory nature of the study, it was strongly felt that a qualitative rather than quantitative approach provided more in-depth insight into the phenomenon of halal maternity wear. Qualitative content analysis is an observational research method used to analyse the symbolic content of all forms of recorded communication (Kolbe and Burnett, 1991). This may comprise several forms, including, images and words. Here, the content analysis relies more on the analysis of meanings from communication modes, as opposed to more traditional quantitative content analysis that has a greater focus on "counting". Website content analysis is a common approach used in research examining product characteristics and assortments for sale online (Kawamura, 2020; Rowley, 2009; Strebinger and Rusetski, 2016).

\section{Data collection}

Data collection consisted of 24 clothing brands and online retailers' websites, scanned for the availability of pregnancy clothing for Muslimah customers. The focus of this investigation was on outfits/outwear clothes only. To locate websites, Google search engine was used. Search words and phrases included: "Islamic maternity clothing", "modest maternity dress", "maternity wear", "Islamic fashion", "halal + maternity wear", "Muslim pregnancy clothing" and "Muslim pregnancy wear". These search phrases were thought to be reflective of how a Muslimah customer would conduct a search on her own behalf. Here, those brands captured by the search terms were considered appropriate as part of the data set for consideration. Additionally, some known Western designer brands were also included in the research due to their periodic Islamic fashion campaigns. Although not exhaustive, 24 sites were considered an appropriate number for analysis as it was believed this number robustly reflected the upper end of the number and range a pregnant customer might be exposed to and consider in a targeted search period. A mixed spread of country origin (including those from Muslim majority populations and those from Muslim minority countries) was used to allow comparison. This also acknowledged that women living in the West have access to a wide range of websites. Therefore, it was important to reflect the variety of brands and different product country of origin women are able to purchase from online. A key inclusion criterion was that sites were either in English or had an English translation option available. Including sites that were English-based or offering an English option meant products on such sites would be accessible to diasporic and Western-born Muslimah living in Western countries, where English would be a language they were most possibly familiar with. The study research team comprised two researchers who were very familiar with Islam practice and beliefs (considered expert to assess the modesty of apparel items from a halal perspective) and the third researcher an expert in childbirth and women's health.

\section{Analysis}

As a foundation, researchers first determined the questions that would interrogate each website. These was ultimately used to create a code book. A list was made that included origin of the website (country of origin); clothing brands; type of range (whether specifically pregnancy garments or other non-pregnancy lines suggestive as suitable for pregnancy, halal only or incorporating both non-halal and halal); main apparel items/product assortment (for example, tunics, dresses, trousers); general characteristics of the garments (colour, material, length, coverage and design features to accommodate the pregnant abdomen e.g. fabric volume, pleating, gathers); how halal was communicated, wording used and patterns of dialogue, (e.g. halal, modest); models and stances/imagery appropriateness to convey halal
Tensions of halal maternity wear 
and finally researcher impressions of the site regarding halal appropriateness/authenticity. Initially, five sites were reviewed by two of the researchers to ensure the codes covered website content holistically. Final codes were settled upon that provided a comprehensive sweep of website content. This process was first undertaken by two researchers independently who then came together to discuss and reach final agreement.

Following this, further data collection was undertaken primarily by one researcher, but with frequent referral to the other two researchers. This referral meant cross checking of coding allocation and impressions was made by researchers coming together to discuss coding and evaluations. Any variation in impressions was discussed between the researchers and a resolution reached. Inter-rate reliability was high (around 97\% average across categories). Data was recorded on an excel spreadsheet. Interpretation of the coding process led to the identification of general classifications discussed in the findings section (a condensed summary of content analysis data is provided as an Appendix to the article).

\section{Findings}

Following the first scanning, initial classification of maternity wear outlets revealed the following groupings: Islamic outlets, non-Islamic outlets, modest brands, semi-modest brands and targeted Islamic wear campaigns. Islamic outlets target mainly Muslimah customers and offer appropriate outfit clothing for pregnant Muslimah to wear. The online retailers such as urbanmodesty.com (USA), shukronline.com (Jordan), poplook.com (Malaysia) offer maternity and nursing clothes made considering most aspects of Islamic wear in public. The clothes offered in these outlets are designed to be ablution (wudhu) friendly which makes it easier for pregnant women to ritually purify themselves for salah (prayers). Models are featured with hijab advertising the products on these outlets. NonIslamic outlets do not target pregnant Muslimah customers. These outlets do not offer appropriate outfits specifically tailored for them. The clothing offered in Forever New (Australia), H\&M (Sweden), Zara (Spain), DKNY (USA) represent "incorrect" outfit wear for pregnant Muslimah customers.

Modest brands offer modest clothing. However, these clothes can still be considered inappropriate for pregnant Muslimah to wear in public. The clothes of Nee See's dresses (USA) are described as modest and suitable wear for church functions. These clothes can be possibly worn comfortably indoors by pregnant and nursing Muslimah. However, these clothes are not designed for veiled Muslimah in non-Mahram settings. Semi-modest brands offer some appropriate outfit clothing for pregnant Muslimah. The brands such as GAP (USA), Net-a-Profit (UK), 3 Bears Maternity (NZ), Mrs Smith (NZ)'s maternity clothing can be worn by veiled Muslimah. Islamic clothing campaigns usually do not offer Islamic outfits. These offer one-off or annual Islamic fashion collections. In this category, we identify ten brands: Dolce and Gabbana (Italy), Nike (USA), Tommy Hilfiger (USA), Mango (Spain), Uniqlo (Japan), Burberry (UK), Zara (Spain), DKNY (USA), H\&M (Sweden) and Net-a-Profit (UK). From these brands, Dolce and Gabbana, Nike, Tommy Hilfiger, Burberry, DKNY do not produce maternity clothing. These brands introduce Islamic/Ramadan collections or hijabi model-featured advertisings during 2014-2020. For example, Mango (Spain) launched "Ramadan Collection" in 2016. Notably however, it received backlash for failing to understand Muslimah consumers perhaps due to doing insufficient prior research on "Islamic" clothing. In particular, the singular use of "waif like models with mousey hair" was deemed inappropriate for a market consisting of women of many skin types and risked the brand being seen as exploitative (https://nationalpost.com/life/fashion-beauty/upset-overuse-of-pale-waif-models-to-sell-ramadan-collections).

After the second scanning, brands were classified into three groups: 
(1) non-Islamic brands that periodically produce clothing specifically for Muslimah/ pregnant Muslimah;

(2) Islamic brands targeting Muslimah/pregnant Muslimah; and

(3) non-Islamic brands that do not specifically target Muslimah/pregnant Muslimah.

Tensions of halal maternity wear

The analysis is focused on the first and second types of brands. The third type of brand was excluded from the analysis, due to the irrelevant nature of the brands.

It is evident that several problems exist when brands attempt to target Muslim customers. Our analysis of evidence reveals the following problems. First, marketers tend to conduct insufficient research required for in-depth understanding of Muslimah consumers and their goals, aspirations and problems. Second, marketers tend to neglect the spiritual side of dressing modestly. The range of products currently offered place excessive emphasis on non-spiritual factors. Third, marketers tend to excessively focus on Middle Eastern customers when designing Islamic clothing collections and communication campaigns. As Muslims can be of any ethnicity, marketers often fail to correctly address the needs of local Muslimah customers and make locally appropriate designs. Indeed, speaking of the vast degree of "variegation" of American Islam both religiously and ethnically, Curtis (2017) asserts that Muslim (Americans) are the most racially diverse religious group of any in America. Fourth, there appears to be an apparent lack of authenticity (i.e. sincere intention) when targeting Muslimah customers. Customers may interpret some marketing practices as a focus on profit and money making, rather than the manifestation of being sincerely concerned about pressing issues related to maternity. Fifth, marketers tend to offer clothes without taking into consideration local climate/weather patterns. Finally, marketers carry a very limited range of outfit clothing that are specifically made for pregnant women. Often, pregnancy outfit clothing is simply linked to plus size clothing.

\section{Discussion}

Based on our findings, this study reveals several issues related to the availability and promotion of halal maternity wear online, particularly when addressing the needs of Western Muslimah. Successful marketing solutions to the problems of halal maternity wear require solving a number of tensions arising at the intersections of the following distinctions: mahram versus non-mahram settings, crude versus stylish fashion and the normative perceptions of immodesty versus modesty.

\section{Dynamism of "mahram" versus "Non-Mahram" settings}

The principles of halal labelling would not strictly apply in the maternity-wear context. Although explicit halal labelling may help with identification and classification, it might also create feelings of fear, suspicion and risk (Wilson and Liu, 2011). Rather, halal would be more reflected in how Muslim women navigate the dynamics of mahram versus nonmahram milieus. In such milieus, pregnant Muslimah would be driven by motives such as convenience (personal privacy), intimacy (spouse's company), functionality (household work) or ethics (in the presence of children and elderly) or conspicuousness (family gatherings). These choices would still be subject to local socio-cultural beliefs, norms, traditions and rituals. The "non-mahram" setting (when one finds herself in the company of the "other", i.e. people who are potentially eligible to marry or have sexual relationships with her) may become activated in many unexpected ways (e.g. a stranger unexpectedly entering the room with no warning). Hence, the main challenge of Muslim women tends to be quick 
transition from/to Islamic maternity wear. Maternity wear marketers must consider the complexities of such transitions.

\section{Social tensions related to maternity wear fashion}

The conformity to the Islamic principles does not mean that halal maternity wear can be devoid of taste. The current trends of halal wear bear the burden of the disparaging attacks from the two distinct socio-cultural bases:

(1) religious fundamentalists who believe that women's wear must be crude and basic; and

(2) the so-called "secular modernists" who see any religiously inspired clothing as "ugly", "backward” or "threatening" (Sandikc1 and Ger, 2005, 2007).

Ironically, these two extreme views tend to reinforce each other's positions. The authors believe that the optimal perspective must be formulated from a moderate position which should recognise not only functional aspects of maternity wear but also its emotional, symbolic, experiential, connective, social and self-expressive facets.

The notions such as modest fashion or Islamic modern clothing tend to attract politically and ideologically charged debates regarding the role of fashion, a creative mode of selfexpression, within the orthodoxy of Islamic rulings. Asking if being both modest and fashionable is possible, Wilson (2016) indicates that the term "modest Muslim fashion" is misleading. As the case of Indonesian movement of Hijabers indicates, beauty and taste is an integral part of fashion (Wilson, 2016). Anas Sillwood, the CEO of the leading Islamic clothing brand SHUKR, states that Muslims should dress well and look presentable. To support his words, he mentions the hadith of the Prophet Muhammad SAW, "God is beautiful and He loves beauty" (Sillwood, 2016). He argues that Muslims should always take a moderate approach in worldly matters including fashion, while using clothing and fashion as a means for reaching their spiritual goals.

Hence, wearing the right/modest clothing is seen as an expression of faith and religious righteousness among Muslims. Maternity wear is not simply the fabric that covers the Muslimah's body, but also it is the manifestation of spirituality and devotion. Imam Omar Suleyman mentions the Islamic term of "ihsan" when commenting on the SHUKR brand, "This is Ihsan in clothing, MashaAllah" (www.shukr.co.uk/). Here, the Arabic word "ihsan" means beautification and excellence. Clothing is considered to be part of religious worship. Ihsan means sincerity and devotion, while wearing the best clothing to maintain strong connection to God indicates a unique motive. This motive is distinct from the assumed motives of "fitting in", social conformance and ritualism.

\section{Maternity wear and modesty}

The Oxford dictionary refers to modesty as "the action of behaving or dressing so that you do not show your body or attract sexual attention". Islam encourages both Muslim males and females to dress modestly when they are out in public. This expectation also applies to pregnant Muslimah. Wilson et al. (2013) argue that modern marketing in Islamic societies is gradually transforming "modesty" into a branded means of both inconspicuous and conspicuous consumption. They further argue that modesty now is less about being frugal or shy, rather it is becoming more about visible beauty and aesthetics that has a "proselytizing" function. In this article, we emphasise the richness of cultural differences as well as interpretive flexibility pertaining to the modesty of maternity wear. Muslims tend to develop their own understanding of modest wear. Some veiled Muslim women choose to dress in loose clothes made from thick, pattern-free, dark-coloured fabrics. However, others 
can freely wear colourful, patterned, fitted clothes. In both cases, women are inspired by their culture shaped by the socio-historical development of localised Islamic traditions. In addition, factors such as climate, population density and labour conditions might significantly affect patterns of outfit selection.

\section{Halal maternity-wear matrix}

The Halal Maternity-Wear Matrix derived from the study findings (Table 1) shows the different categories of clothing observed. The matrix attests to the complexity of Muslim women's maternity wear decisions depending on circumstances. It indicates that impermissibility is only activated within few settings depending on the features of maternity wear (the upper two blocks in the non-mahram setting).

The Halal Maternity-Wear Matrix indicates different contexts in which different features of maternity garments might gain relevance. It is certain that maternity fashion for women practising Islam is not monolithic. For clothing to become truly Islamic, seamless contextual switching, i.e. conveniently moving between mahram and non-mahram settings, must be ensured. Making maternity-wear halal does not mean a call to embark on a religious "crusade" against "infidel" global brands (Izberg-Bilgin, 2012). Rather, it is about "cultural osmosis", i.e. gradual assimilation of tastes (Wilson and Grant, 2013).

\section{Conclusion}

Our study has drawn attention to the attractiveness and potentially lucrative nature of halal maternity wear for online brands of both Islamic and non-Islamic origin. Indeed, several brands of Western country of origin are already attempting to engage with this market, some better than others. As pregnancy is a time where a woman needs to feel good about her physical and psycho-social state, the availability of maternity clothing that meets her needs well will assist in making this life stage and the transition toward motherhood a positive experience. While pregnant Muslim women face the same issues brought about by the physical changes of pregnancy experienced by all gestating women, the contextual distinctions that Western non-Muslim women apply in regard to maternity wear choices do not directly transcribe to Muslim women. However, there is no doubt that fashionability which incorporates an appropriate level of modesty in a maternity garment will be more attractive to pregnant Muslim women than those garments promoted as halal, but "miss the

Context I: Mahram environment

Mahram

Basic/Crude

Modesty

Non-modest

Personal privacy (for the self; no restrictions when alone)

Modest Functional clothing (e.g. household chores)

Context II: Non-mahram environment

Fashion

Non-mahram Basic/Crude

Modesty

Non-Modest

Impermissible

Modest

Islamic wear (e.g. religious purposes, prayer)
Tensions of halal maternity wear . 
mark". What is required is the coordinated (systems) approach to developing marketing systems that genuinely tend to the needs of pregnant Muslimah, while creating the marketas-the-public-good that takes Islamic distinctions into account (Kadirov, 2018).

Through the content analysis of websites sourced using search terms considered to be reflective of those that Western-based Muslim women would use in a search for maternity clothing, we demonstrate the wide, and sometimes inappropriate, range of offering. In this way our study makes a significant contribution to knowledge about the characteristics and promotion of halal maternity wear. Despite evidence that younger Muslimah women are interpreting Islamic principles vis-à-vis their apparel in new ways, the fundamentals of underlying Islamic teachings remain as the bottom line of successful halal maternity wear markets. We conclude that for manufacturers and brands to harness approval and establish themselves as authentic in this market, careful research and care needs to be taken before promoting and targeting their products as appropriate for Muslimah maternity wear. Those brands that display the requisite skills and knowledge necessary to determine whether a product meets the needs of modesty, fashionability and local climate/weather conditions, while incorporating the necessary components of garment construction to accommodate pregnancyspecific physical changes have much to gain from the Muslimah maternity market. Correspondingly, good online access to appropriate and desirable maternity wear for Muslimah in the West will greatly assist in promoting wellbeing during the liminal stage of pregnancy.

As a limitation, we acknowledge that the voice of pregnant Muslimah consumers is not present in this study. This addition would enhance findings in relation to how website offerings are actually perceived by the target market. In-depth interviews with Muslimah on their online purchase decision process and consumption experience of maternity garments would add valuable insights. It would also be worthwhile examining how product design and authenticity vis-a-vis Islamic requirement for dress is approached by brands, with comparison across the various brands discussed. Also, localised perspectives on modesty and maternity wear should be further investigated. We suggest all these considerations be a topic for future research.

\section{References}

Akou, H.M. (2007), "Building a new 'world fashion': Islamic dress in the twenty-first century", Fashion Theory, Vol. 11 No. 4, pp. 403-421.

Anand, N. (2012), "Smart maternity wear': an answer to longevity problem of maternity wear", Journal of Textile and Apparel Technology and Management, Vol. 7 No. 3, pp. 1-8.

Behrman, J.A. and Erman, J. (2019), "An exploration of differences in ideal family size between muslim and non-Muslim women in France", Demographic Research, Vol. 41, pp. 617-648.

Boulanouar, A.W. (2006), "The notion of modesty in Muslim women's clothing: an Islamic point of view", New Zealand Journal of Asian Studies, Vol. 8 No. 2, pp. 134-156.

Cassar, L. (2006), "Cultural expectations of Muslims and orthodox Jews in regard to pregnancy and the postpartum period: a study in comparison and contrast", International Journal of Childbirth Education, Vol. 21 No. 2, pp. 27-30.

Curtis, E.E. (2017), The Practice of Islam in America: An Introduction, New York, NY University Press. New York, NY.

Earle, S. (2003), "Bumps and boobs': fatness and women's experiences of pregnancy", Women's Studies International Forum, Vol. 26 No. 3, pp. 245-252.

Ghodrati, F. and Akbarzadeh, M. (2018), "A review of the importance of maternal-fetal attachment according to the islamic recommendations", Journal of Midwifery and Reproductive Health, Vol. 6 No. 1, pp. 1193-1200. 
Haddad, Y. and Smith, J. (Eds) (2014), The Oxford Handbook of American Islam, Oxford University Press.

Hammoud, M., White, C. and Fetters, M. (2005), "Opening cultural doors: providing culturally sensitive healthcare to Arab American and American Muslim patients", American Journal of Obstetrics and Gynecology, Vol. 193 No. 4, pp. 1307-1311.

Hassan, S.M., Leavey, C. and Rooney, J.S. (2019), "Exploring English speaking Muslim women's firsttime maternity experiences: a qualitative longitudinal interview study", BMC Pregnancy and Childbirth, Vol. 19 No. 1, p. 156, doi: 10.1186/s12884-019-2302-y.

Hassan, S.M. (2017), "A qualitative study exploring British Muslim women's experiences of motherhood while engaging with NHS maternity services", Doctoral dissertation, Liverpool John Moores University.

Izberg-Bilgin, E. (2012), "Infidel brands: unveiling alternative meanings of global brands at the nexus of globalization, consumer culture, and Islamism", Journal of Consumer Research, Vol. 39 No. 4, pp. 663-687.

Johnson, S., Burrows, A. and Williamson, I. (2004), "Does my bump look big in this? The meaning of bodily changes for first-time mothers-to-be", Journal of Health Psychology, Vol. 9 No. 3, pp. 361-374.

Jones, C. (2007), "Fashion and faith in urban Indonesia", Fashion Theory, Vol. 11 Nos 2/3, pp. 211-232.

Kadirov, D. (2014), "Islamic marketing as macromarketing", Journal of Islamic Marketing, Vol. 5 No. 1, pp. 2-19.

Kadirov, D. (2018), "Towards a theory of marketing systems as the public good", Journal of Macromarketing, Vol. 38 No. 3, pp. 278-297.

Kadirov, D., Allayarova, N. and Boulanouar, A.W. (2016), "Transformation as reversion to fitrah: Muslim Māori women's self-transformation through reflexive consumption”, Journal of Business Research, Vol. 69 No. 1, pp. 33-44.

Karyono, G., Ahmad, A. and Asmai, S.A. (2017), "Survey on nudity detection: opportunities and challenges based on 'awrah' concept in Islamic Shari'a”, Journal of Theoretical and Applied Information Technology, Vol. 95 No. 15, pp. 3450-3460.

Kawamura, Y. (2020), Doing Research in Fashion and Dress: An Introduction to Qualitative Methods, Bloomsbury Publishing, London.

Kim, M.O., Suh, M.A. and Lee, Y.H. (2010), "Development of maternity wear trousers with improved body fit", Journal of the Korean Society of Clothing and Textiles, Vol. 34 No. 5, pp. 715-725.

Kolbe, R.H. and Burnett, M.S. (1991), "Content-analysis research: an examination of applications with directives for improving research reliability and objectivity", Journal of Consumer Research, Vol. 18 No. 2, pp. 243-250.

Krisjanous, J., Richard, J.E. and Gazley, A. (2014), "The perfect little bump: does the media portrayal of pregnant celebrities influence prenatal attachment?", Psychology and Marketing, Vol. 31 No. 9, pp. 758-773.

Lesley, A. (2016), "Getting to know Zahra Aljabri, Muslim co-founder of modest clothing store", World Religion News (30 August, 2016), available at: www.worldreligionnews.com/?p=30474 (accessed December 2020).

Longhurst, R. (2005), "(ad) dressing pregnant bodies in New Zealand: clothing, fashion, subjectivities and spatialities", Gender, Place and Culture, Vol. 12 No. 4, pp. 433-446.

Merits, M., Sildver, K., Bartels, I. and Meejärv, K. (2018), “The cultural customs of Afghanistan Muslims during pregnancy, childbirth and postpartum period", GPH-International Journal of Health Sciences and Nursing, Vol. 1 No. 1, pp. 1-28.

Miller, L.J. (2014), "Psychological, behavioral, and cognitive changes during pregnancy and the postpartum period", (Chapt 2) in the Oxford Handbook of Perinatal Psychology, in Wenzel, A. (Ed.), Oxford Handbooks Online, Oxford, pp. e1-33.

Mossière, G. (2012), "Modesty and style in Islamic attire: refashioning Muslim garments in a western context", Contemporary Islam, Vol. 6 No. 2, pp. 115-134. 
Musial, J. (2003), “Pregnancy chic': the marketing of maternity wear”, Journal of the Motherhood Initiative for Research and Community Involvement, Vol. 5 No. 1, pp. 159-171.

Ogle, J.P., Tyner, K.E. and Schofield-Tomschin, S. (2013), "The role of maternity dress consumption in shaping the self and identity during the liminal transition of pregnancy", Journal of Consumer Culture, Vol. 13 No. 2, pp. 119-139.

Qaradawi, Y. A-. (1995), The Lawful and the Prohibited in Islam, Islamic Book Trust, Kuala Lumpur.

Rowley, J. (2009), "Online branding strategies of UK fashion retailers”, Internet Research, Vol. 19 No. 3, doi: $10.1108 / 10662240910965397$.

Russo, J. (1995), "The structure of emotion: psychophysiological, cognitive and clinical aspects", The Journal of Nervous and Mental Disease, Vol. 183 No. 3, p. 190.

Sandıkcı, Ö. and Ger, G. (2005), "Aesthetics, ethics and politics of the Turkish headscarf", in Kuechler S. and Miller, D. (Eds), Clothing as Material Culture, Berg, Oxford, pp. 61-82.

Sandıkcı, Ö. and Ger, G. (2007), "Constructing and representing the Islamic consumer in Turkey", Fashion Theory, Vol. 11 Nos 2/3, pp. 189-210.

Sillwood, A. (2016), "Interview with the CEO", available at: www.shukrclothing.com/international/blog/ interview-with-the-ceo/

Sohn, M. and Bye, E. (2015), "Pregnancy and body image: analysis of clothing functions of maternity wear", Clothing and Textiles Research Journal, Vol. 33 No. 1, pp. 64-78.

Strang, V.R. and Sullivan, P.L. (1985), "Body image attitudes during pregnancy and the postpartum period”, Journal of Obstetric, Gynecologic, \& Neonatal Nursing, Vol. 14 No. 4, pp. 332-337.

Strebinger, A. and Rusetski, A. (2016), "Prioritizing geo-references: a content analysis of the websites of leading global luxury fashion brands", Journal of Global Marketing, Vol. 29 No. 5, pp. 282-297.

Williams, A. (2018), "The practice of Islam in America", Journal of Muslim Philanthropy and Civil Society, Vol. 2 No. 2.

Wilson, J.A. (2014), “The halal phenomenon: an extension or a new paradigm?”, Social Business, Vol. 4 No. 3, pp. 255-271.

Wilson, J.A. (2016), "Marketing modest fashion or fashioning modesty?", Maestro, pp. 89-91.

Wilson, J.A., Belk, R.W., Bamossy, G.J., Sandikci, Ö., Kartajaya, H., Sobh, R., Liu, J. and Scott, L. (2013), "Crescent marketing, Muslim geographies and brand Islam", Journal of Islamic Marketing, Vol. 4 No. 1, pp. 22-50.

Wilson, J.A. and Grant, J. (2013), "Islamic marketing - a challenger to the classical marketing canon?", Journal of Islamic Marketing, Vol. 4 No. 1, pp. 7-21.

Wilson, J.A.J. and Liu, J. (2011), “The challenges of Islamic branding: navigating emotions and halal”, Journal of Islamic Marketing, Vol. 2 No. 1, pp. 28-42.

Zaidi, A.Z. (2017), "Perinatal mental health and Islam", British Journal of Midwifery, Vol. 25 No. 12, pp. $761-764$.

\section{Further reading}

Ilyas, S. (2012), "Is Muslim fashion finally 'on trend'?", The Guardian, April 26, 2012, available at: www.guardian.co.uk/fashion/fashion-blog/2012/apr/26/muslim-fashion-on-trend

Thompson Reuters and Dinar Standard (2019), An Inclusive Ethical Economy: State of the Global Islamic Economy, Report 2018/19, Thomson Reuters.

\section{Corresponding author}

Jayne Krisjanous can be contacted at: jayne.krisjanous@vuw.ac.nz 


\section{Appendix}

Tensions of

halal

wear

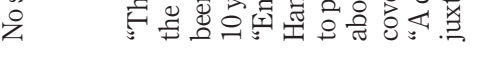

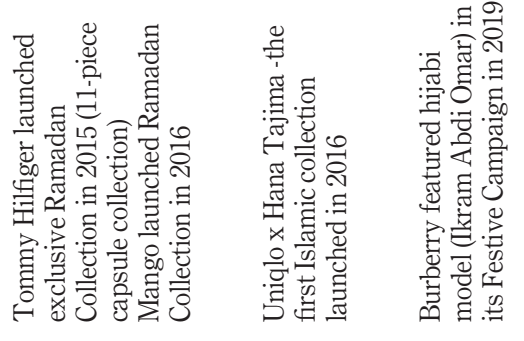

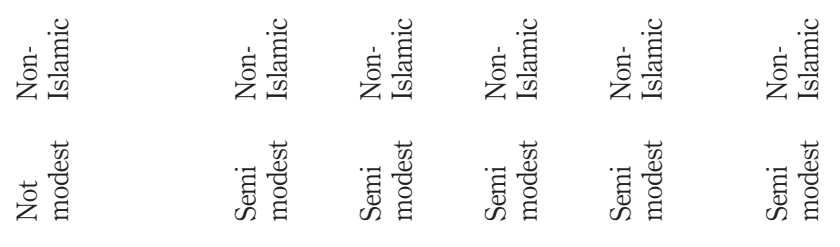


JIMA

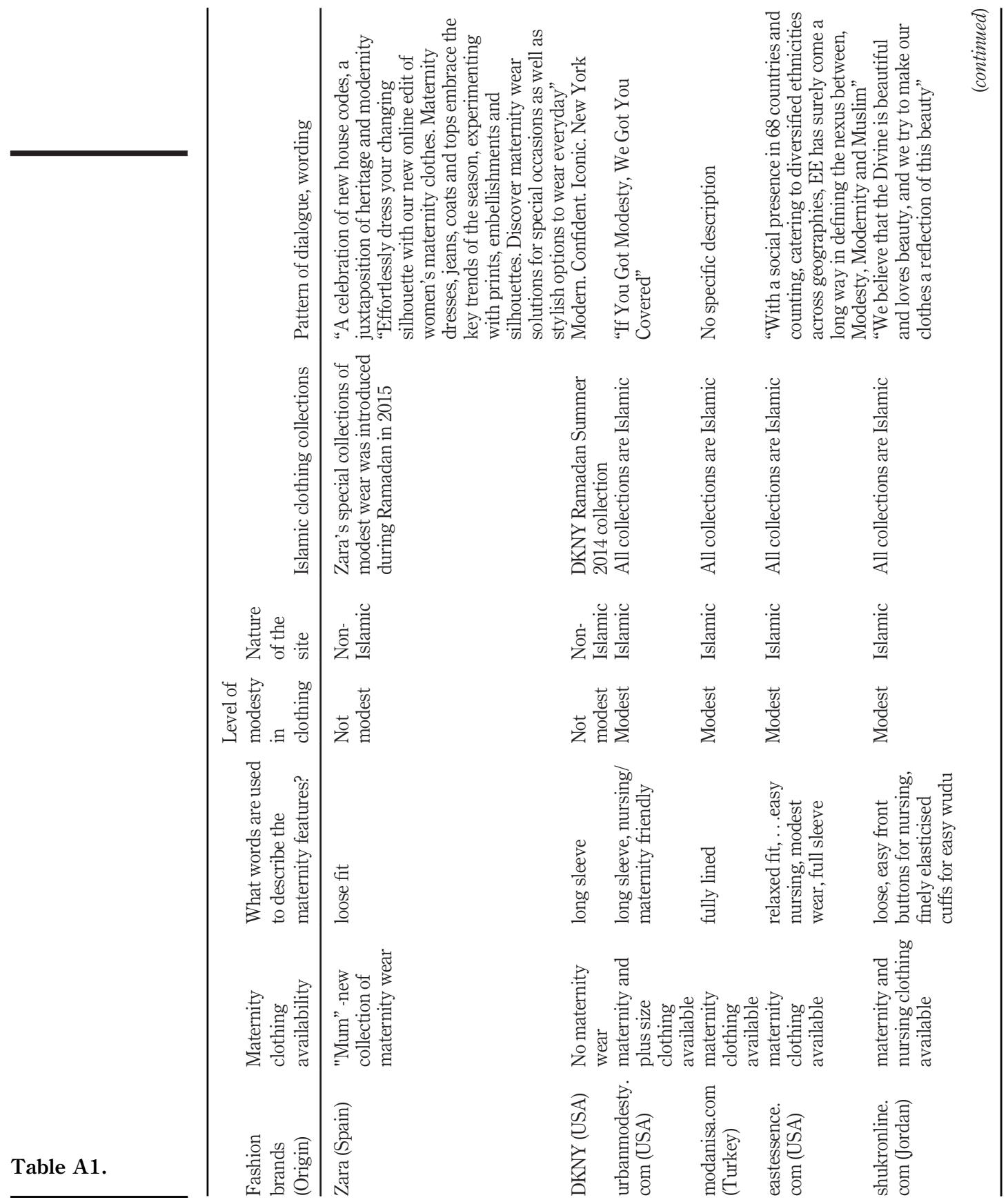




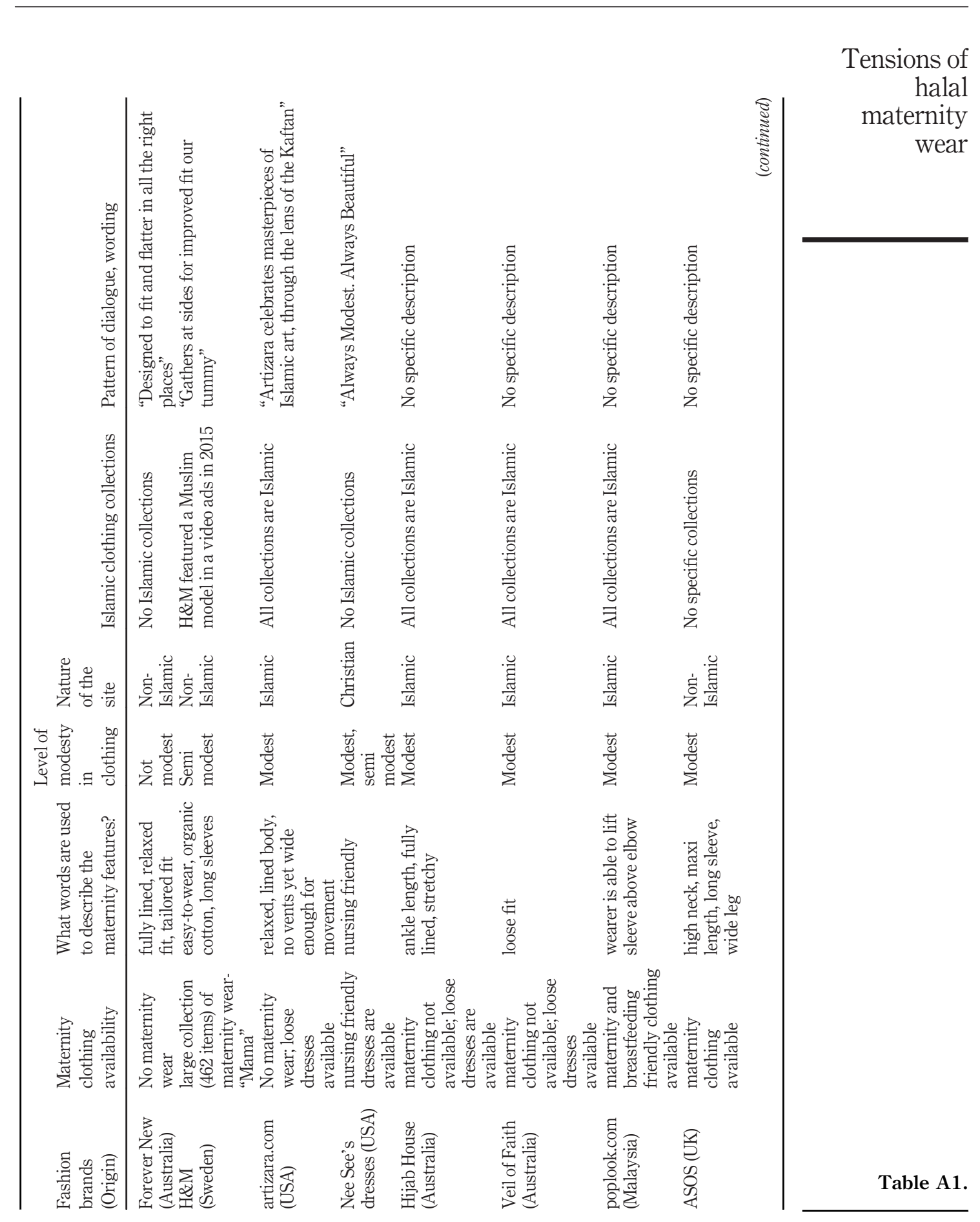


JIMA

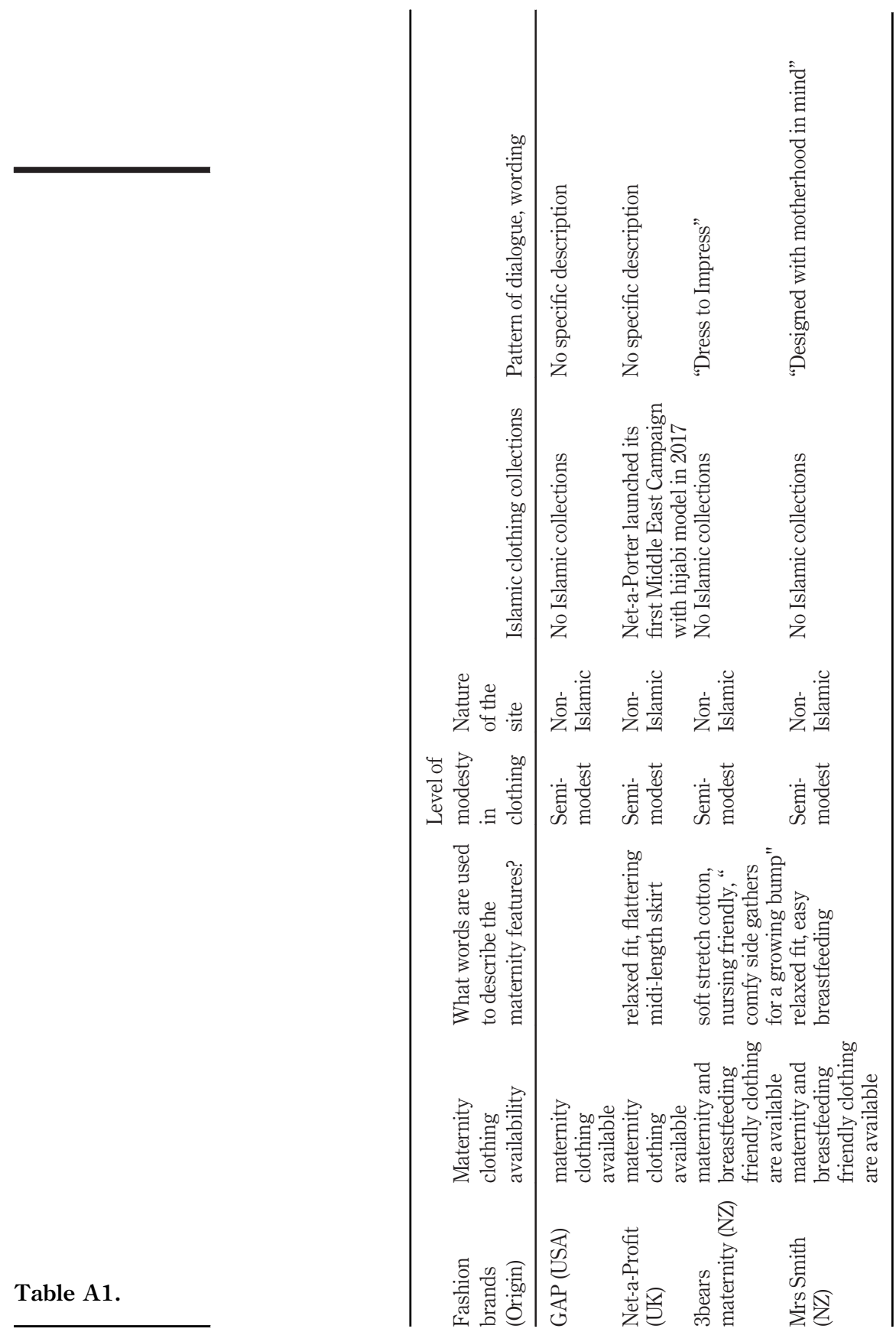

